\title{
Limiting long-term illness and subjective well-being in families
}

\author{
Cara L Booker \\ cbooker@essex.ac.uk \\ Amanda Sacker \\ University of Essex \\ Institute for Social and Economic Research \\ Colchester, UK
}

(Received May 2011 Revised October 2011)

\begin{abstract}
The definition of subjective well-being (SWB) includes subjective perceptions of moods such as happiness and cognitive judgements of life satisfaction coupled with an absence of negative feelings. Little is known about levels of well-being within families when other family members have a limiting long-term illness. This paper explores these associations. Data come from year 1 wave 1 of Understanding Society, a new longitudinal UK-representative household panel survey. Subjective well-being of adults ( $\geq 16$ years) was measured using the GHQ-12, the Short Warwick-Edinburgh Mental Well-being Scale and a life satisfaction question. The Strengths and Difficulties Questionnaire measured well-being in youth (aged 10 to 15 years). Self-reported limiting long-term illness (LLTI) was the measure of illness. Latent variable models were used to explore associations between partners $(N=5,236)$ and among older parent's LLTI and adult children's SWB ( $n=184)$. A two-level, one-with-many model was used to examine associations between parents illness and youth SDQ total difficulties scores $(n=1,491)$. Associations between adult child LLTI and older parent SWB were also explored as well as the relationship between having a young child with needs in the household and parent SWB. LLTI in one member of a cohabiting partnership was negatively associated not only with their own well-being but also that of their partner. This association appeared to be confounded by the severity of their illness. There was no association between a parent's LLTI and their adult child's well-being. There was a significant association between a parent's LLTI and SDQ total difficulties score for youth. This association was reduced when controlling for caring for the youth, and further attenuated by the physical and mental functioning of the parent. There was no association of adult child LLTI with older parents' SWB. The findings from this study indicate that the limiting illness of one family member has a differential association with the well-being of other family members. Partners, youth and parents of youth had lower levels of SWB when a family member had a LLTI. These associations were largely accounted for by caring behaviours and physical and mental functioning. SWB among adult children and older parents was unchanged whether or not one resided with a person (older parent or adult child) with a LLTI.
\end{abstract}

Keywords: limiting long-term illness, subjective well-being, family, Understanding Society 


\section{Introduction}

Subjective well-being (SWB) is a multidimensional, multi-component construct that has been associated with changes in a person's life. There are two main components to SWB, 1) Emotional or affective responses and 2) Cognitive responses (Diener 1994). Positive affect (i.e. happiness, joy, contentment etc) and negative affect (i.e. sadness, anxiety, depression etc) comprise the emotional or affective component, while life and domain satisfaction (i.e. work, family, health etc) assessments comprise the cognitive component (Diener 1994 ; Diener et al 1999 ; Cronin de Chavez et al 2005). Exploring intrapersonal changes in well-being in response to different stressors or events has long been a subject of research (Diener 2000 ; Clark et al 2001 ; Lucas et al 2003 ; Cronin de Chavez et al 2005 ; Lucas 2005 ; Luhmann and Eid 2009 ; Clarke and Georgellis 2010). More recently however researchers have begun to look at intrapersonal changes in SWB due to events experienced by others in their familial or social networks (Berg and Upchurch 2007 ; Fekete et al 2007 ; Giannakopoulos et al 2009 ; Pruchno et al 2009 ; Dorros et al 2010 ; Sieh et al 2010).

Much of this work has looked at couple relationships and the effect of a specific illness in one partner on the well-being or coping behaviour of their partner. The health conditions examined include dementia (Lieberman and Fisher 1995 ; Poulin et al 2010), end stage renal failure (Pruchno et al 2009), congestive heart failure (Luttik et al 2009), psychosis (Kuipers et al 2007), lupus (Fekete et al 2007) and cancer (Banthia et al 2003 ; Dorros et al 2010). With one exception, these studies of patient and spousal caregiver dyads investigated relationships between factors such as coping style or type of support on well-being. They did not quantify the potential impact of chronic illness per se on the couple's well-being. The study by Luttik et al (2009) was the exception. It compared couples with an ill partner with matched healthy partner dyads, finding small differences in well-being between the two groups. This study, in common with others based on patient samples, relied on small numbers of partner dyads. Also, because many of the criterion disorders were conditions that predominantly occur in later life, the couples were sampled from the older population. Most studies did not report on the impact of the ages of the couple, but those that did were inconclusive
(Gerstorf et al 2009 ; Poulin et al 2010). It remains unclear whether these previous findings can be generalised. Does limiting long-term illness (LLTI) have negative ramifications for the partnership's well-being and are effects different for older and younger pairs?

While the effects of LLTI on well-being within partner relationships are important, there may be other members of the household who could also be affected by an illness in the family. A few studies have examined the association between parental illness and child well-being with varied results. In adult children, no association was observed between severity of parental dementia and child well-being (Lieberman and Fisher 1995). However, the adult children in their study were living away from their parents. We found no published data on the impact of a parent's limiting long-term illness with respect to adult children living in the same household. Younger children on the other hand, do seem to be affected by parental ill health, with decreases in quality of life and increases in problem behaviours (Giannakopoulos et al 2009 ; Kelly and Bartley 2010 ; Sieh et al 2010). This raises the question of whether adult children living with an ill parent will have poorer well-being or not. In the United Kingdom (UK) there are approximately 28 million households with dependent children and around 3 million adult children, aged 20-34 years, living with their parents (Office for National Statistics 2009b; Office for National Statistics 2010). The 2001 UK census found that around 15 percent of 30-59 year old adults had a LLTI. Therefore there are large numbers of children of all ages who could be affected by poor health in the family.

Parental well-being while caring for a chronically sick or disabled child has also received some attention. One study found little difference in family functioning between families with and without a child with a chronic condition, although this was not confirmed in a recent large study which found that caregivers of children with health problems had more than twice the odds of reporting physical and mental health problems than caregivers of healthy children (Rodrigues and Patterson 2007 ; Brehaut et al 2009). Mothers of sick or disabled children had poorer well-being than mothers of healthy children (Hirst 2005). In fact this study found women to be more affected than men 
across a range of caring situations. The caregiving role as the mechanism relating illness and wellbeing within the household or among family members has been the focus of much research (Lieberman and Fisher 1995 ; Kuipers et al 2007 ; O'Reilly et al 2008 ; Siegrist and Wahrendorf 2009 ; Llewellyn et al 2010 ; Poulin et al 2010). Familial caregivers experience increased stress and poorer health due to the requirements of their roles, compared to family members who are not caregivers (Stajduhar et al 2010). Yet recent research has shown that caregivers have lower mortality risks than non-caregivers (O'Reilly et al 2008). Cross-national European research has also shown differences in the quality of life between informal helpers, voluntary workers and caregivers (Siegrist and Wahrendorf 2009). The number of informal caregivers is expected to increase in the UK with the ageing of the population over the next two decades (Office for National Statistics 2009a). Therefore it is important to examine these associations in a representative UK population and to understand whether well-being outcomes are explained by the caregiving role or not. Even when the mechanism appears to be related to caregiving, it is possible that this is confounded by the degree to which one's illness impacts on daily living (Lieberman and Fisher 1995). More disruptions to daily activities by one's illness is likely to be associated with greater functional limitations. Functional problems reduce opportunities for social engagement among other family members, besides the affected individual.

The research to date raises several unanswered questions which this study seeks to address. We examine the relationship of limiting long-term illness (LLTI) with SWB between partners, as well as the effect of parental LLTI on adult and younger children and the SWB of parents caring for a child with illness or disability.

The specific research questions were:

1. Is there an association between illness of:

a. One partner and the well-being of the other partner?
b. A parent and the well-being of their children?
c. A child and the well-being of their parents?

2. What is the effect of caregiving or being cared for on these associations?

3. Are there gender differences in these relationships?

4. Are there age differences in that:

a. The associations are greater or smaller for partners above retirement age compared to partners below retirement age?

b. The associations are greater or smaller for young children compared to adult children?

\section{Methods}

\section{Participants}

Data for this study come from first year of the first wave of Understanding Society, the UK Household Longitudinal Study (UKHLS). The UKHLS is a nationally representative longitudinal household study, which began in 2009. With an aim of recruiting over 100,000 individuals in 40,000 households, the data collection period takes two years to complete one wave of the study; thus at the time of writing, only one half of the first wave has been released for analysis. More detailed information on the sampling frame and data collection procedures are available (Burton et al 2011).

Flow charts of the data sources and sample sizes for the full first wave and the data used in this study are provided in figures $1 \mathrm{a}$ and $1 \mathrm{~b}$. In total over 40,500 households were interviewed in wave 1 , of these 25,324 were interviewed in year 1 . The data used in this study come from the New Generation Population Sample only, a nationally representative sample of 14,103 households. The exclusion of single-person households provided an analysis sample of just over 10,000 households. 
Figure 1a. Understanding Society household sample size flow chart

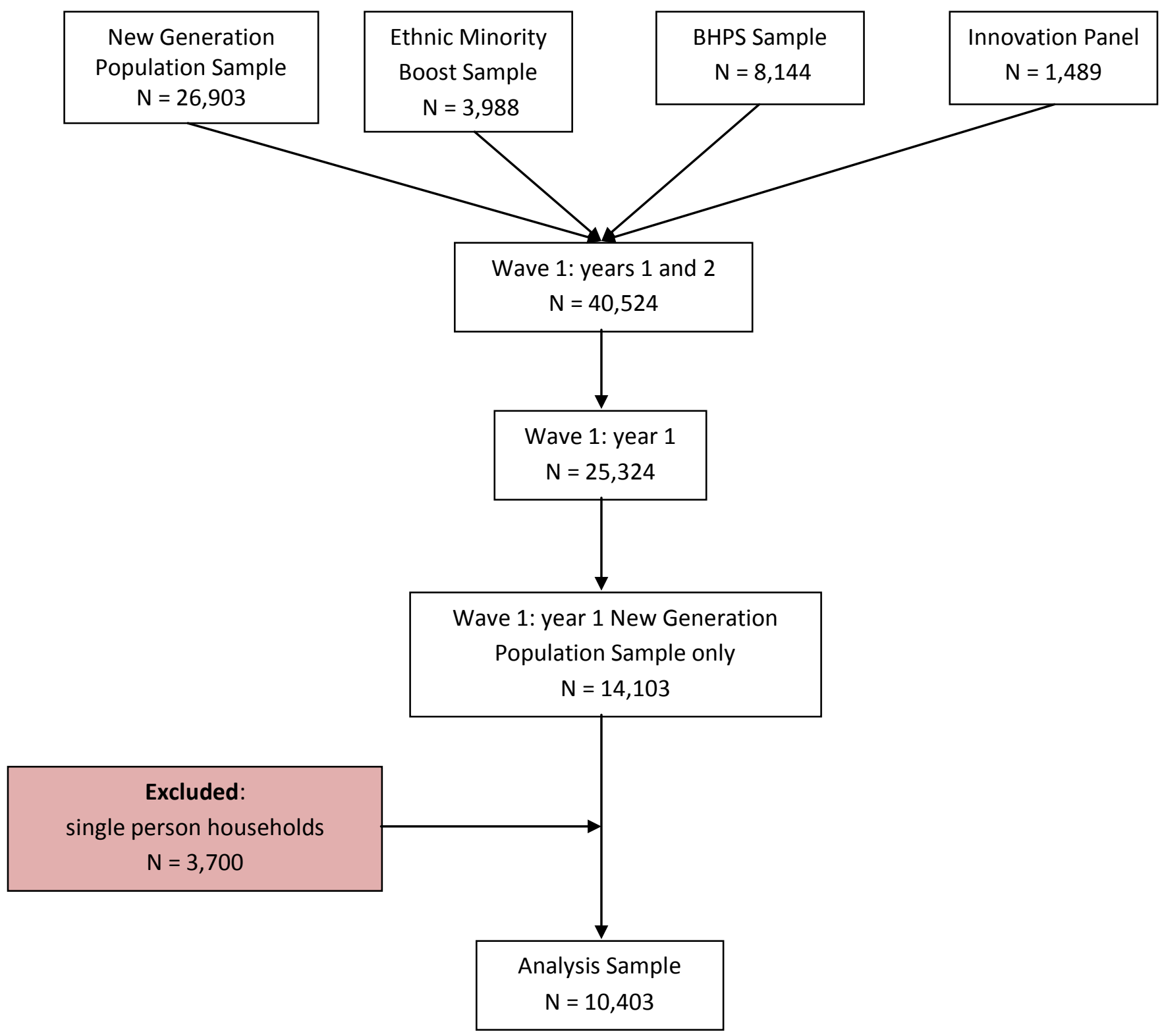

The analysis sample was then split into three sub-samples, figure $1 \mathrm{~b}$. The couple sample consists of all cohabiting partners, irrespective of marital status or gender. The adult child sample consists of adult children who lived with a parent over the current UK retirement age of 60 for females and 65 for males. We wished to differentiate between households with adult children who had yet to leave the family home, and households where an older parent had perhaps returned to live with their married offspring. There were too few of the former type of household where a parent had a LLTI for analysis, so we focus on households where there was a parent over retirement age. The youth sample is drawn from all young people aged 10-15 years who lived with one or more parents.

All persons in the household aged 10 and older are eligible to be surveyed annually. Young people, aged 10-15, are given a self-completion youth questionnaire. This survey asks questions about their daily activities, health behaviours, and family and peer relationships. Adults, 16 and older, are given a combination of computer-assisted personal interview (CAPI) and self-completion questionnaire. The topics covered include subjective well-being, employment status, health status and various other economic and social topics. 
As can be seen in figure $1 \mathrm{~b}$, additional cases were excluded for various reasons. The majority of these cases were excluded due to non-completion of the self-completion portion of the survey by one or more parties. Over 3,000 households were excluded from the partners sample, 303 from the adult children sample and 530 households from the youth sample. The outcomes of interest, described later, are all assessed in the self-completion portion of the survey.

The augmented samples include the missing data which has been imputed. Thus for the partner sample, with imputation there are 5,236 partners, however, complete case analysis had only 4,499 partners. Imputation of the adult children sample added 21 cases, while 111 cases were added for the youth sample.

\section{Figure $\mathbf{1 b}$. Analysis sample size flow chart}

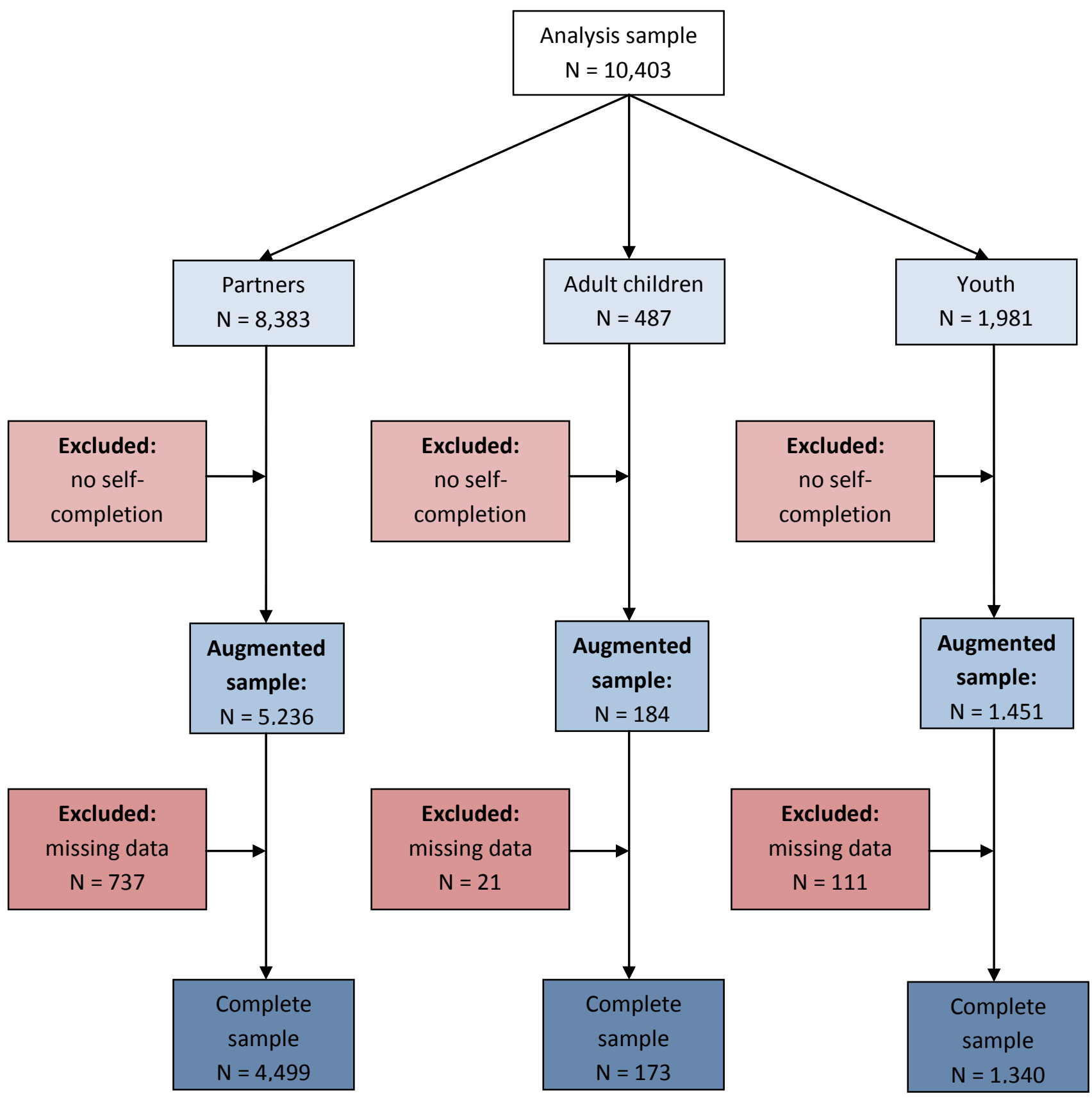




\section{Measures}

\section{Adult measures \\ Limiting long-term illness}

Limiting long-term illness (LLTI) status was a dichotomous variable determined from two questions. The first question asks "Do you have any long-term physical or mental impairment, illness or disability? By 'long-term' I mean anything that has troubled you over a period of at least 12 months or that is likely to trouble you over a period of at least 12 months." If the participant answered yes to this question then they are asked about the type of impairments/disabilities that may limit or cause "substantial difficulties" in their life. Participants who experienced any limiting impairment/disability were categorized as having a LLTI, while all others were categorised as not having a LLTI.

These questions and definitions of LLTI have been utilised in UK and international cross-sectional and longitudinal surveys and have been validated in several studies for both elderly and adult populations (Cohen et al 1995 ; Payne and Saul 2000 ; Power et al 2000 ; Manor et al 2001).

\section{Subjective well-being}

Three different measures of subjective wellbeing (SWB) were used to create a latent construct of adult well-being. The GHQ-12 was used to measure psychological distress (Goldberg and Williams 1988 ; Goldberg et al 1997). The responses to the 12 items are scored on a 0-1-2-3 scale and summed to produce a total score ranging from 0 36; this is known as the GHQ Likert-scoring method. A higher score indicates higher levels of psychological distress or poorer well-being.

The 7-item Short Warwick-Edinburgh Mental Well-being Scale (SWEMWBS) (Stewart-Brown et al 2009) was used as a measure of positive psychological well-being. The items, with responses from "none of the time" to "all of the time," are scored on a Likert scale from 1 to 5 . The items are summed to give a total score, ranging from 7 to 35 , where higher scores indicate higher levels of wellbeing.

The final measure of SWB was life satisfaction. This single item question worded "Please tick the number which you feel best describes how dissatisfied or satisfied you are with the following aspects of your current situation" was asked of respondents who scored the question on a 7-point Likert scale ranging from 1 (Completely dissatisfied) to 7 (Completely satisfied).

\section{Youth measures \\ Limiting long-term illness}

Youth were not asked about their health status. As a proxy for LLTI among youth, we used information on caring, asked of parents. All adult participants were asked whether they cared for someone in their household who was "sick, disabled or elderly," and who that person in the household was. If a parent indicated that they cared for a child aged between 10 and 15, then the child was deemed to have a LLTI.

\section{Strengths and Difficulties Questionnaire}

The Strengths and Difficulties Questionnaire (SDQ) is an instrument used to screen for behavioural problems in children aged 3 to 16 years (Goodman et al 1998 ; Goodman 1999). The SDQ is made up of 25 items which are scored on a 3-point Likert scale and can be summed into five subscales (Emotional problems, Conduct problems, Hyperactivity/inattention, Peer relationship problems and Pro-social behaviour). The first four subscales are summed to create a total difficulties score, which is used in this study. The SDQ was completed by the young person as part of the selfcompletion questionnaire.

\section{Covariates and potential confounders}

Four analyses were carried out: LLTI and SWB between couples; parental LLTI and adult child wellbeing; parental LLTI and younger child well-being; and child LLTI with parent well-being. A variable that measures caring for one's partner was included as a potential confounder in the couple analysis. For the parental LLTI and adult child well-being analysis, caring for one's parent was included. As the caring question was only asked of adults 16 and older, there is no equivalent information on whether youth cared for a parent. For the child LLTI with parent well-being analysis, a variable was created to indicate whether any children in the household, under the age of 16 , required care. All variables were scored $0 / 1$ with 1 indicating caring.

The 12-item Short Form Health Survey (SF-12) is an instrument used to measure health functioning in a general population sample (Ware et al 2001). The physical and mental component summary scales (PCS and MCS) were employed here. Both scales have scores that range from 0 to 100 . These scores were normalised to the 1998 United States population to have a mean of 50 and a standard deviation of 10 (Ware et al 2001). Both the PCS and 
MCS were included in models as potential confounders.

Age, age squared, gender, highest attained education, and previous month household income were included as covariates. Age was included as a continuous variable centred on the grand mean. An age squared term, of the centred age variable, was included to examine whether there were any nonlinear relationships between SWB and age. Gender was dichotomised with female as the reference group. Highest attained education was a derived variable scored on a 6-point scale with a low of "no qualifications" to a high of "degree." Previous month household income was also a derived variable that included all sources of income from the month prior to interview. Previous month household income was adjusted for inflation and household size using the modified OECD scale (OECD 2009) and then log-transformed.

While length of partnership may also be considered as a covariate for the partnership data, preliminary analysis showed that length of partnership and age were highly correlated, $\kappa=$ $0.85 \mathrm{p}$-value $<0.0001$. Therefore length of partnership was not included.

\section{Statistical analyses}

Four types of model were used in the analysis of the data: a latent variable actor-partner interdependence model (APIM) for the couple's analysis; a latent variable one-with-many design for the parent-adult child well-being analyses; an observed variable one-with-many design for the parent-younger child well-being analyses; and a clustered latent variable model for the child-parent well-being analyses. Full information on the modelling strategy can be found in Appendix 1.

The latent variable APIM (Cook and Kenny 2005 ; Kenny et al 2006), used to observe associations between the LLTI status and subjective well-being of partner dyads, is comprised of two parts: a measurement model describing the relationship between a latent well-being variable and the three indicators of well-being (GHQ-12, SWEMWBS and life satisfaction), and a structural model that estimates the paths between dependent and independent variables, the variance and covariance between independent variables and the variance of the error in the dependent variable (Kline 2010).

In order to explore the relationship between the LLTI of parents over retirement age and their coresident adult children's well-being, a one-with- many design was used. This was specified as a twolevel latent variable model, with children at level 1 nested within parents at level 2 .

The third type of analysis examined the association between parents' LLTI status and their young child's SDQ total difficulties score. This onewith-many model was again estimated using a twolevel model, with children at level 1 nested within parents at level 2. While SWB was measured using a latent variable in the adult child analysis, here observed SDQ measures indicate younger children's well-being.

The fourth and final type of analysis was that used to model the relationship between having a child in the household in need of care, and the wellbeing of their parents. A latent variable model is estimated, taking account of the clustering of mothers and fathers within households.

Three models were fitted successively for each type of analysis: 1) a baseline model examining effects on latent/observed SWB as the dependent variable(s) associated with own and other family members LLTI as independent variables (IVs), controlling for household income, gender, linear and quadratic terms for age, and highest attained education of the family members; 2 ) the baseline model with added covariate(s) showing if the family member whose well-being is being assessed is a carer for the family member with a LLTI ; and 3) a final model with, additionally, the health functioning score(s) of the family member with a LLTI.

Multiple imputation was conducted using the ice command (Royston 2009) in STATA (StataCorp 2009), to create 20 augmented datasets. Descriptive analyses were conducted in SAS Version 9.1 (SAS Institute Inc. 2003). All modelling was carried out using MPlus 6 software (Muthén and Muthén 1998-2010). All models were estimated using the robust maximum likelihood option which provides "maximum likelihood parameter estimates with standard errors and chi-square tests of model fit that take into account non-normality of outcomes and non-independence of observations due to cluster sampling" (Muthén and Muthén 1998-2010). All regression estimates and standard errors provided are from multiply imputed data. Descriptive statistics given in the paper are based on the imputed cases, descriptive statistics for the complete case data can be found in Appendix 3 . 


\section{Results}

Table 1. Descriptive statistics of partners by age group*

\begin{tabular}{|c|c|c|c|c|c|c|c|}
\hline \multirow{2}{*}{ LLTI (\% Yes } & \multicolumn{2}{|c|}{$\begin{array}{l}\text { Overall } \\
N=5236\end{array}$} & \multicolumn{2}{|c|}{$\begin{array}{l}16-59 / 64 \\
n=3953\end{array}$} & \multicolumn{2}{|c|}{$60 / 65+$} & \multirow[t]{2}{*}{ p-value } \\
\hline & & & & & & & \\
\hline Partner 1 & 24 & -- & 18 & -- & 40 & -- & \\
\hline Partner 2 & 28 & -- & 25 & -- & 40 & -- & \\
\hline \multicolumn{8}{|c|}{ Care for Partner (\% Yes) } \\
\hline Partner 1 & 6 & -- & 4 & -- & 12 & -- & \\
\hline Partner 2 & 5 & -- & 3 & -- & 12 & -- & \\
\hline \multicolumn{8}{|l|}{ Age } \\
\hline Partner 1 & 49.04 & 3.38 & 42.30 & 7.78 & 69.83 & 5.87 & $<0.0001$ \\
\hline Partner 2 & 49.39 & 3.39 & 42.82 & 8.42 & 69.61 & 6.35 & $<0.0001$ \\
\hline \multicolumn{8}{|c|}{ GHQ Score } \\
\hline Partner 1 & 10.78 & 4.94 & 10.93 & 11.47 & 10.32 & 9.98 & 0.0001 \\
\hline Partner 2 & 10.81 & 6.55 & 11.02 & 12.59 & 10.16 & 10.17 & $<0.0001$ \\
\hline \multicolumn{8}{|c|}{ SWEMWBS } \\
\hline Partner 1 & 18.40 & 4.39 & 18.19 & 10.24 & 19.06 & 8.90 & $<0.0001$ \\
\hline Partner 2 & 18.61 & 5.58 & 18.42 & 11.31 & 19.19 & 9.00 & $<0.0001$ \\
\hline \multicolumn{8}{|c|}{ Life Satisfaction } \\
\hline Partner 1 & 5.42 & 1.42 & 5.32 & 3.28 & 5.72 & 2.85 & $<0.0001$ \\
\hline Partner 2 & 5.39 & 1.41 & 5.29 & 3.29 & 5.66 & 2.86 & $<0.0001$ \\
\hline \multicolumn{8}{|c|}{ SF-12 Physical Functioning } \\
\hline Partner 1 & 49.61 & 11.02 & 51.54 & 24.39 & 43.68 & 21.14 & $<0.0001$ \\
\hline Partner 2 & 51.76 & 9.22 & 51.24 & 21.21 & 53.36 & 18.37 & $<0.0001$ \\
\hline \multicolumn{8}{|c|}{ SF-12 Mental Functioning } \\
\hline Partner 1 & 48.79 & 14.76 & 50.17 & 30.13 & 44.57 & 23.80 & $<0.0001$ \\
\hline Partner 2 & 51.90 & 15.52 & 51.39 & 23.69 & 53.48 & 19.38 & $<0.0001$ \\
\hline
\end{tabular}

* Age, Partner 1 and 2 GHQ-12 Score, Partner 1 and 2 SWEMWBS Score and Partner 1 and 2 Life Satisfaction Score are means and standard deviations; SWEMWBS = Short Warwick-Edinburgh Mental Well-being Scale; LLTI = Limiting Long-term IIIness; SF-12 PCS and MCS = Short Form 12-item Physical and Mental Component Scores ${ }^{+} p$-value for Age, Partner 1 and 2 GHQ-12 Score, Partner 1 and 2 SWEMWBS Score, Partner 1 and 2 Life Satisfaction Score and Partner 1 and 2 SF-12 Physical and Mental Functioning based on mean comparisons

\section{Partners and LLTI}

There were 4,499 partner dyads with complete data, however this increased to 5,236 with imputation. Table 1 provides overall descriptive statistics for all individuals in the partner dyads and stratified statistics by age (those who are younger than the current UK retirement age and those who are of retirement age or older). While the majority of partners fall within the same age group, about $8 \%$ of the partnerships have one partner who is in a different age group than the other. As expected, more participants over the retirement age had a LLTI than those who were younger. A greater proportion cared for their partner in the older group as well. Both partners in the older group had significantly better well-being across all SWB measures compared to partners from the younger age group. This was despite the older group having significantly worse physical functioning, as measured by the SF-12, than the younger group. Consistent with their better wellbeing, the older group also had significantly better mental functioning than the younger group.The fit of the measurement models for latent SWB was assessed prior to modelling the full latent variable models. Well-fitting measurement models were found for all family models. Standardised estimates for the measurement model for the APIM model for the younger and older age groups are given in Appendix 2. 
Table 2 provides the results for the three models fit to the partner data, stratified by actor (partner 1) age group. Model 1 is the baseline model which controlled for the age, age squared, gender, education of both partners and household income. In both age groups there was a negative association between own and partner's LLTI, and own and partner's latent SWB. However the effect of partner's LLTI was weaker than the effect of own LLTI (i.e. partner 2 illness on partner 1 well-being was smaller, coefficient $=-0.63$ Standard Error (SE) $=0.21$, than the association between partner 2 illness and partner 2 well-being, coefficient $=-0.43$ $\mathrm{SE}=0.20$ ). Model 2 includes a potential confounder, partner caring. In the younger cohort, there was slight attenuation of the association between LLTI and SWB for both partners. Being cared for by one's partner showed a large and significant negative relationship with SWB for both partners, coefficient $=-3.52$ SE 0.63 for partner 1 care for partner 2, and coefficient $=-2.95$ SE 0.43 partner 2 care for partner 1 . There was no association between caring for one's partner and own SWB. Similar results were observed in the older cohort with one exception. Like the younger group, being cared for resulted in lower SWB but the effects were not as strong as for the younger cohort. Dissimilar to the younger age group, there was a significant negative association between partner 2 caring for partner 1 on partner 2 SWB, coefficient $=-0.99 \mathrm{SE}=0.33$, but no reverse association was found.

In the final model (Model 3), SF-12 physical and mental functioning scores were included. For both partners and age groups, PCS and MCS, higher functioning was associated with better SWB. Following the pattern of Model 2 there was further attenuation of the association between LLTI and SWB for both partners in the younger age group. In fact the association between partner's LLTI and own SWB became non-significant for partner 1 but not for partner 2, coefficient $=-0.33 \mathrm{SE}=0.15$. The relationship between own LLTI and own SWB was much smaller than that seen in Models 1 and 2 and became non-significant for partner 2 . The effects of being cared for by one's partner on own SWB became non-significant for partner 1; however for partner 2 the association was only reduced, coefficient $=-0.87 \mathrm{SE}=0.37$. In the older cohort, there was complete attenuation of all associations for both partners. 
Table 2. Structural Equation Model Estimates for Associations Between Partner's Illness and Subjective Well-being ${ }^{+}$

\section{Model 1 (M1): Baseline \\ Model 2 (M \\ + Caring}

Coefficient SE

Age 16-59/64

Partner 1 LLTI

Partner 2 LLTI

Partner 1 Care for Partner 2

Partner 2 Care for Partner 1

Partner 1 PCS

Partner 1 MCS

Partner 2 PCS

Partner 2 MCS

\section{Age 60+/65+}

Partner 1 LLTI

Partner 2 LLTI

Partner 1 Care for Partner 2

Partner 2 Care for Partner 1

Partner 1 PCS

Partner 1 MCS

Partner 2 PCS

Partner 2 MCS

$\begin{array}{llll}-2.42 * * * * & 0.19 & -0.43^{*} & 0.20 \\ -0.63 * * * & 0.21 & -2.15^{* * * *} & 0.25\end{array}$

\section{Partner 1 SWB \\ Coefficient SE}

$-2.17^{* * * *}$
-0.13
-0.58

0.19
0.21
0.45

Partner 2 SWB

Coefficient SE

$\begin{array}{ll}-0.90^{* * * *} & 0.20 \\ -1.59 * * * * & 0.25 \\ -3.52 * * * * & 0.63 \\ -0.05 & 0.40\end{array}$

Partner 1 SWB

Model 3: M2 + Fu

Partner 1 SWB

Coefficient SE

$-0.41^{* * *}$
0.05
-0.12
0.13
$0.06^{* * * *}$
$0.24^{* * * *}$

$0.24 * * * *$

\subsection{4}

0.14

0.31

0.32

0.01

0.01

$0.05^{* * * *} \quad 0.01$

$0.23^{* * * *} \quad 0.01$

\begin{tabular}{|c|c|c|c|c|c|c|c|c|c|c|c|}
\hline$-1.94 * * * *$ & 0.21 & $-0.43 *$ & 0.20 & $-1.53^{* * * *}$ & 0.21 & -0.30 & 0.21 & -0.30 & 0.16 & -0.20 & 0.15 \\
\hline \multirow[t]{7}{*}{$-0.54 * * *$} & 0.20 & $-2.21 * * * *$ & 0.22 & $-0.68^{* * *}$ & 0.23 & $-1.49 * * * *$ & 0.22 & -0.20 & 0.16 & -0.23 & 0.17 \\
\hline & & & & 0.51 & 0.32 & $-1.94 * * * *$ & 0.38 & 0.20 & 0.22 & -0.38 & 0.29 \\
\hline & & & & $-2.45^{* * * *}$ & 0.45 & $-0.99 * * *$ & 0.33 & -0.31 & 0.34 & -0.14 & 0.23 \\
\hline & & & & & & & & $0.06 * * * *$ & 0.01 & & \\
\hline & & & & & & & & $0.18 * * * *$ & 0.01 & & \\
\hline & & & & & & & & & & $0.06^{* * * *}$ & 0.01 \\
\hline & & & & & & & & & & $0.18^{* * * *}$ & 0.0 \\
\hline
\end{tabular}

$\begin{array}{llll}\text { CFI } & 0.939 & 0.937 & 0.956 \\ \text { TLI } & 0.921 & 0.917 & 0.942 \\ X^{2} & (d . f .=126, N=5236)=579.83, p<0.0001 & (d . f .=142, N=5236)=624.86, p<0.0001 & (d . f .=176, N=5236)=684.29, p<0.0001 \\ \text { RMSEA } & 0.037 & 0.036 & 0.033\end{array}$

0.939 0.037

Partner 2 SWB

Coefficient SE

$\begin{array}{ll}-0.33^{*} & 0.15 \\ -0.31 & 0.18\end{array}$

0.18

$\begin{array}{ll}0.16 & 0.27\end{array}$

$0.18^{* * * *} \quad 0.01$

* $<0.05 ; * *<0.01 ; * * *<0.001 ; * * * *<0.0001$

${ }^{+}$All models controlled for Partner 1 and Partner 2 Age, Age squared, Gender, Education and Household Income; SWB = Subjective Well-being; 95\% Cl = 95\% Confidence Interval; SE = Standard Error; PCS = Physical Component Score; MCS = Mental Component Score; d.f. = Degrees of Freedom; RMSEA = Root Mean Square Error of Approximation 


\section{Adult children and retirement age parents with a LLTI}

Table 3 provides descriptive statistics for adult children living with their parents who were of retirement age and older. Preliminary analysis of the data showed no difference by parental gender in the association between parental LLTI status and adult child's well-being, so both mothers and fathers are pooled in this analysis.
Among the adult children, there were no significant differences for any of the variables of interest between males and females. Analysis of the associations between parental LLTI and adult child SWB resulted in no significant associations (results not shown): illness of parents did not have any effect on their adult children's well-being.

\section{Table 3. Descriptive Statistics of Adult Children and Youth by Gender*}

\begin{tabular}{|c|c|c|c|c|c|c|c|}
\hline \multirow{2}{*}{$\begin{array}{l}\text { Adult Children ( } \mathbf{n}=\mathbf{2 5 4}) \\
\text { Gender (\%) }\end{array}$} & \multicolumn{2}{|c|}{ Overall } & \multicolumn{2}{|c|}{ Males } & \multicolumn{2}{|c|}{ Females } & p-value ${ }^{+}$ \\
\hline & & & 57 & -- & 43 & -- & \\
\hline Adult Child LLTI (\% Yes) & 36 & -- & 36 & -- & 34 & -- & \\
\hline Parent LLTI (\% Yes) & 43 & -- & 40 & -- & 46 & -- & \\
\hline Care for Parent (\% Yes) & 18 & -- & 16 & -- & 21 & -- & \\
\hline Age & 36.47 & 7.96 & 36.75 & 13.89 & 36.08 & 32.68 & 0.80 \\
\hline GHQ-12 Score & 11.5 & 6.59 & 11.38 & 8.86 & 11.67 & 13.59 & 0.74 \\
\hline SWEMWBS Score & 17.47 & 5.47 & 17.16 & 7.22 & 17.88 & 11.42 & 0.32 \\
\hline Life Satisfaction Score & 5.07 & 1.60 & 4.95 & 2.13 & 5.23 & 3.20 & 0.16 \\
\hline \multicolumn{8}{|l|}{ Youth $(n=3074)$} \\
\hline Gender (\%) & & & 51 & -- & 49 & -- & \\
\hline Cared for by Parent (\% Yes) & 2 & -- & 3 & -- & 1 & -- & \\
\hline Parent LLTI (\% Yes) & 19 & -- & 21 & -- & 18 & -- & \\
\hline Age & 12.49 & 0.05 & 12.43 & 0.01 & 12.55 & 0.21 & 0.19 \\
\hline SDQ Total Diffculties Score & 11.16 & 5.60 & 11.35 & 7.91 & 10.96 & 11.21 & 0.05 \\
\hline Parent SF-12 PCS & 51.79 & 9.91 & 51.73 & 13.62 & 51.85 & 19.36 & 0.74 \\
\hline Parent SF-12 MCS & 49.52 & 10.12 & 49.40 & 14.20 & 49.63 & 20.16 & 0.53 \\
\hline
\end{tabular}

\footnotetext{
* Age, SDQ Total Difficulties Score, GHQ-12 Score, SWEMWBS Score and Life Satisfaction Score are means and standard deviations; $S D Q=$ Strengths and Difficulties Questionnaire; SWEMWBS = Short Warick-Edingburgh Mental Well-being Scale; LLTI = Limiting Long-term IIIness; SF-12 PCS and MCS = Short Form Physical and Mental Component Scores
}

${ }^{+}$p-value for Age, GHQ-12, SWEMWBS, Life Satisfaction, SDQ Total Difficulties Score and Parent SF-12 Physical and Mental Functioning based on least squares mean comparisons

\section{Youth and parents with a LLTI}

Among youth, there were an equal proportion of boys and girls and the mean age was not significantly different between genders (Table 3). Parents reported caring for boys more (3\%) than girls (1\%). Unfortunately, we have no information on whether a child cared for their parent. More boys had parents with a LLTI (21\%) than girls (17\%). There was no difference between boys' and girls' SDQ total difficulties scores. There were also no significant differences in parental physical or mental functioning scores by child gender.

The results from the three models that were estimated for youth are provided in Table 4. Again, preliminary analysis of the data showed nonsignificant differences in the association between parental LLTI status and youths' SDQ scores by the gender of the parent, therefore the associations are pooled. There was an association between parents' 
LLTI and youth SDQ total difficulties: the children of ill parents had higher SDQ scores than children with non-ill parents, coefficient $=1.05 \mathrm{SE}=0.29$. In Model 2, parental caring for the child was included as a potential confounder. Both parental LLTI, coefficient $=0.83 \mathrm{SE} 0.28$, and caring for child, coefficient $=5.01 \mathrm{SE}=0.77$, were significantly associated with higher SDQ scores, but there was some attenuation of the former association between parental LLTI and the SDQ.

Table 4. Structural Equation Model Estimates for Associations Between Parent's Illness and Youth's Well-Being ${ }^{+}$

Model 1 (M1): $\quad$ Model 2 (M2): $\quad$ Model 3: M2 + Baseline M1 + Caring Youth SDQ Youth SDQ Functioning Coefficient SE Coefficient SE Coefficient SE

Parent's LLTI $1.05^{* * * *} \quad 0.29$ $0.83^{* * *} \quad 0.28$ $0.13 \quad 0.35$

Care for Child $5.01^{* * * *} \quad 0.77$ $4.84 * * * * \quad 0.76$ Parental SF-12 PCS $-0.03 *$ 0.01 Parental SF-12 MCS $-0.05^{* * * *} \quad 0.01$

\footnotetext{
* $<0.05$; ${ }^{*}<0.01 ; * * *<0.001 ; * * * *<0.0001$
}

${ }^{+}$All models controlled for Parent and Child Age, Age squared, Gender, Parent Education and Household Income; SDQ = Strengths and Difficulties Questionnaire; SE = Standard Error; LLTI = Limiting Long-term IIIness; SF-12 PCS and MCS = Short Form Physical and Mental Component Scores

The final model included the SF-12 PCS and MCS functioning scores of the parent. There was complete attenuation of the effect of parental LLTI on youth SDQ scores with the addition of these scores. In both cases, there was a significant negative association between SF-12 functioning score and youth SDQ total difficulties score, PCS coefficient $=0.03 \mathrm{SE}=0.01$; MCS coefficient $=0.05$ $\mathrm{SE}=0.01$. Parental care for the youth remained a significant predictor of SDQ difficulties, coefficient = 4.84 SE $=0.76$.

\section{Retirement age parents of adult children with a LLTI}

In the final set of analyses we examined the associations between adult child illness and parental SWB. The sample used to examine the association between adult children and parents was the same as that used to examine parental LLTI on adult child SWB.
We found no association between adult child LLTI and parental SWB.

\section{Parents of young children in household in need of care}

The final set of analyses also examined the associations between having a child in the household in need of care and parental SWB. A larger sample was used to examine the association between caring for a young child in the household and parental SWB. As there is no direct measure of LLTI for young children in Understanding Society, child illness was identified according to whether the child required care or not. Therefore we examined whether there were any young children, i.e. those of 15 years of age and younger, in the household and in need of care.

There was an association between having a child in the household who required care and parental SWB, Table 5, coefficient $=0.92 \mathrm{SE}=0.30$. 


\section{Table 5. Structural Equation Model Estimates for Associations Between Child in Household in Need of Caring and Parent's Subjective Well-being ${ }^{+}$ \\ Model 1 (M1): Baseline Parent SWB}

III Child in Household

$\mathrm{CFI}$

TLI

$X^{2}$

RMSEA
SE

0.30

\footnotetext{
${ }^{*}<0.05 ; * *<0.01 ; * * *<0.001 ; * * * *<0.0001$

${ }^{+}$All models controlled for Parent Age, Age squared, Gender, Parent IIIness and Household Income; 95\% Cl = 95\% Confidence Interval; SE = Standard Error; SWB = Subjective Well-being; d.f. = Degrees of Freedom; RMSEA = Root Mean Square Error of Approximation
}

\section{Discussion}

This study has examined the link between illnesses in one family member and the well-being of other members of the household. It takes a life course perspective, examining influences between and across generations, from youth to the postretirement years. The findings were able to provide answers to our four research questions.

With respect to the first question, the findings show cross-partner associations between illness and subjective well-being in earlier and later adult life. An association between parental illness and youth well-being was also observed, as well as an association between having an ill child in the household and parental well-being. However there was no observed relationship between older parents' illness and their adult children's well-being or of adult children's illness and their older parents' well-being. The patterns of these findings suggest that there may be differential associations of illness on well-being depending on the familial relationship and the age of the family members, addressing the fourth research question. Consistent interrelationships between health and well-being were observed for older and younger couples. Yet, while youth had more difficulties, adult children did not appear to be affected by their parents' LLTI. Similarly, parents had lower well-being when there was an ill child in the household, but older parents of adult children with a LLTI did not.
We were interested in examining the effect of being a carer or receiving care as stated by the second research question. Evidence of the impact of caring was observed in two of our analyses. Among partners, the intra-individual relationships between illness and well-being were attenuated by being cared for. These findings suggest that among those who are ill, needing to be cared for by a partner may be more strongly linked to well-being than being ill but still able to care for oneself. These relationships were further attenuated by physical and mental health functioning. This suggests that pathways from functioning of the individual are driving effects on subjective well-being. In other words, the worse the physical and mental functioning of one partner, the more likely it is that they are: 1) cared for by the other partner and 2) have lower well-being. This confounding effect was observed in both older and younger couples. While functioning still confounded the relationship between health and well-being, in the younger group there remained an independent association between own limiting illness and own SWB. This could be because of normative expectations of good health during this period in the life course. Such attitudes might not be maintained later in life.

Further exploration of caring and functioning was done to examine what impact a clinically meaningful change in mental health functioning would have for SWB. A clinically meaningful change 
in health functioning has been recommended to be .5 standard deviates (sd) (Wywich et al 1999; Sacker et al 2008). Our findings showed that caring for a partner with a clinically meaningful change in mental functioning had a four-fold reduction in SWB, compared to caring for a partner without a clinically meaningful change in mental functioning. The small impact of caring on SWB, lends support to recent findings that have shown caregivers to have lower risk of mortality than non-caregivers (O'Reilly et al 2008). The findings suggest that it is not the act of caring that has a large impact on SWB and possibly mortality, but rather the functioning of one's partner that has a larger impact.

Associations between illness and well-being have been seen in other areas of research. A study of women with breast cancer found that an interaction between levels of women's depression and stress contributed to their partner's lower levels of wellbeing (Dorros et al 2010). An additional finding suggested that the combination of higher levels of depression in the cancer sufferer and increased partner stress was associated with poorer physical health in the partner (Dorros et al 2010). However, another study of older people with diabetes and their partners found significant associations between distress relating to diabetes management and depressive symptoms of the partner with diabetes, but only marginal effects on the other partner's depressive symptoms (Franks et al 2010).

Even though almost half of the adult children living with retirement-aged parents had a parent with a LLTI, there was no association between parental illness and their subjective well-being. It is likely that there was not enough power due to small sample size to observe an association. It may also be possible that the adult children were not affected by their parent's illness because they had become used to dealing with any difficulties affecting their parent(s). The cross-sectional data do not allow for further exploration of the immediate and long-term effects of parental LLTI incidence. This lack of association between parental illness and adult child well-being has been found previously (Lieberman and Fisher 1995). In their study, adult children of dementia sufferers had significantly worse somatic symptoms the more severe their parent's dementia, however no significant associations between dementia severity and anxiety and depression or well-being were observed (Lieberman and Fisher 1995). As noted previously, one of the major differences between the referenced paper and this study is where the adult children lived. In this study the adult children lived with the parent with a limiting illness, whereas in the Lieberman and Fisher paper(1995), the only requirement for selection into the study was that the adult child lived within a 50-mile radius of the ill parent. It might be expected that a non-resident carer would not experience the same impact on their own well-being as they would have if they were caring for the ill parent in the same household (Lieberman and Fisher 1995). In support of this argument, the non-resident carers spent on average 6.1 hours per week caring for their parent. A resident child however, would most likely have daily interactions with the ill parent, and more caring duties to perform, so it is somewhat surprising that their well-being was not affected. Future waves of Understanding Society will be able to address whether there are any immediate changes to SWB in association with onset or deterioration of health problems in a co-resident parent, or with changes in household composition due to a sick parent moving into or out of the household.

In contrast to the adult child findings, the analyses of youth found that illness of a parent was associated with an increase in SDQ total difficulties score. These associations were weakened if the child was being cared for by the parent. One possible reason for these findings is that youth, with their own needs which were cared for by a parent, may experience increased difficulties over and above those that came from having an ill parent. There was also an effect of parental physical and mental functioning on the relationship between parental illness and youth SDQ total difficulties score. Youth with parents who had worse functioning had higher SDQ total difficulties scores. This indicates that parents with poor physical or mental functioning may find it more difficult to provide for the emotional needs of the child. It may also be that there is no one else in the household to help provide care for the parent, and the young person is forced into a role of caregiver that they are not emotionally prepared for. While these analyses did not differentiate between lone parent and two-parent households, preliminary analysis found no statistical difference in the SDQ total difficulties score of children of a lone parent with a LLTI, and children in a two-parent household with a LLTI. Similar findings were observed for children of 
healthy parents in a one- or two-parent household. The findings from the youth analysis are consistent with findings from other studies. In another crosssectional analysis, Giannakopoulos and colleagues (2009) observed associations between parental functioning and different adolescent health quality of life measures although their study did not allow for parental gender effects to be examined. We found that it made no difference which parent was ill, although another study found that mothers' health had a greater impact on young children's SDQ scores than fathers' health (Kelly and Bartley 2010). A recently published meta-analysis by Sieh et al. (2010) also found that children of chronically ill parents had more problem behaviours than children of healthy parents, especially among girls and if the mother was ill. However, it was not possible to ascertain if parental gender had different effects for younger or older children. Since life course development of problem behaviours is known to differ by gender (Cohen et al 1993 ; Verhulst 1995), the excess risk of maternal ill health for their children's well-being may also be moderated by age.

Analysis of children's illness on parental well-being yielded conflicting results. There were no significant associations between adult child LLTI and parental SWB. This may be due to the small sample size and a lack of power to observe associations. It may also be that similar to the adult children's well-being having no significant associations with parental LLTI, parents of an adult child with LLTI have adapted to the situation so that their well-being was not any worse than parents living with a healthy adult child. By contrast, having a young child in the household who required care was associated with a significant reduction in parental SWB.

One of the limitations of this study, in common with much of the literature on this subject, is that the analyses are based on cross-sectional data. No conclusions can be made with respect to causality. We were also not able to look at patterns with respect to duration or severity of LLTI. It is possible that there are initial decreases of SWB with onset of illness, that may level off or rebound after family members have made appropriate adjustments to living with a partner, parent or adult child with a LLTI. Conversely, for some people the longer the duration a LLTI, the more disruptive and debilitating the illness becomes, requiring care and perhaps reducing well-being in the family members. Searches of the literature have provided few longitudinal studies examining inter-personal effects of illness on SWB. Future data from Understanding Society will be able to address some of these issues as well explore some of the mechanisms through which illness affects SWB.

Care must be taken when generalising these findings, especially those of the adult children and parents of the adult children. While the data came from the nationally representative New Generation Population Sample of Understanding Society there was a larger percentage of excluded data due to missing self-completion surveys and therefore missing outcome data. There were also few adult children living with their over retirement age parents, however, recent figures show that the number of people over the age of 65 in the UK living with others (excluding spouse or partner) is among the lowest in the European Union (lacovou and Skew 2010). Thus the numbers in this sample appear to be representative. As noted earlier, the small sample size may have resulted in low power to detect associations between adult child and older parent illness and SWB.

\section{Conclusions}

The findings show associations between partner illness and partner SWB, parental illness and youth SDQ total difficulties score, and living with an ill child and parental SWB. There were also potential confounders of these relationships that should be addressed further. It is therefore important that future studies not only examine the relationship between illness and wellbeing in the ill person, but also to explore the immediate and long-term effects on the well-being of those living with the person with a LLTI. Better understanding of these effects may help to inform mental health care workers and other professionals who may be tasked with helping family members care for and cope with their loved one's illness.

\section{Acknowledgements}

This research was supported by the UK Economic and Social Research Council for the United Kingdom Longitudinal Studies Centre (award no. RES-586-47-0001-02) and the Research Centre on Micro-Social Change (MiSoC) (award no. RES-518-28-001). We are very grateful to Yvonne Kelly and the anonymous reviewers for helpful comments and suggestions. 


\section{References}

Banthia R, Malcarne VL, Varni JW, Ko CM, Sadler GR and Greenbergs HL (2003) The effects of dyadic strength and coping styles on psychological distress in couples faced with prostate cancer. Journal of Behavioral Medicine, 26, 31-52.

Berg CA and Upchurch R (2007) A developmental-contextual model of couples coping with chronic illness across the adult life span. Psychological Bulletin, 133, 920-954.

Brehaut JC, Kohen DE, Garner RE, Miller AR, Lach LM, Klassen AF and Rosenbaum PL (2009) Health among caregivers of children with health problems: Findings from a Canadian population-based study. American Journal of Public Health, 99, 1254-1262.

Burton J, Laurie H and Lynn P (2011) Appendix: Understanding Society Design Overview. IN MCFALL, S. \& GARRINGTON, C. (Eds.) Early findings from the first wave of the UK's household longitudinal study. Colchester, UK, Institute for Social and Economic Research, University of Essex.

Clark AE, Georgellis Y and Sanfey P (2001) The psychological impact of past unemployment. Economica, 68, 221-241.

Clarke AE and Georgellis Y (2010) Back to baseline in Britain: Adaptation in the BHPS. Working Paper No. 2010-02. Paris, Paris School of Economics.

Cohen G, Forbes J and Garraway M (1995) Interpreting self reported limiting long term illness. BMJ, 311, 722-724.

Cohen P, Cohen J, Kasen S, Velez CN, Hartmark C, Johnson J, Rojas M, Brook J and Streuning EL (1993) An epidemiological study of disorders in late childhood and adolescence: I. Age- and gender-specific prevalence. Journal of Child Psychology and Psychiatry, 34, 851-867.

Cook WL and Kenny DA (2005) The actor-partner interdependence model: A model of bidirectional effects in developmental studies. International Journal of Behavioral Development, 29, 101-109.

Cronin de Chavez A, Backett-Milburn K, Parry O and Platt S (2005) Understanding and researching wellbeing: Its usage in different disciplines and potential for health research and health promotion. Health Education Journal, 64, 70-87.

Diener E (1994) Assessing subjective well-being progress and opportunities. Social Indicators Research, 31, 103-157.

Diener E (2000) Subjective well-being: The science of happiness and a proposal for a national index. American Psychologist, 55, 34-43.

Diener E, Suh EM, Lucas RE and Smith HL (1999) Subjective well-being: Three decades of progress. Psychological Bulletin, 125, 276-302.

Dorros SM, Card NA, Segrin C and Badger TA (2010) Interdependence in women with breast cancer and their partners: An interindividual model of distress. Journal of Consulting and Clinical Psychology, 78, 121125.

Fekete EM, Stephens MAP, Mickelson KD and Druley JA (2007) Couples' support provision during illness: The role of perceived emotional responsiveness. Families, Systems \& Health, 25, 204-217.

Franks MM, Lucas T, Stephens MAP, Rook KS and Gonzalez R (2010) Diabetes distress and depressive symptoms: A dyadic investigation of older patients and their spouses. Family Relations, 59, 599-610.

Gerstorf D, Hoppmann CA, Kadlec KM and McArdle JJ (2009) Memory and depressive symptoms are dynamically linked among married couples: Longitudinal evidence from the AHEAD Study. Developmental Psychology, 45, 1595-1610.

Giannakopoulos G, Dimitrakaki C, Pedeli X, Kolaitis G, Rotsika V, Ravens-Sieberer U and Tountas Y (2009) Adolescents' wellbeing and functioning: relationships with parents' subjective general physical and mental health. Health and Quality of Life Outcomes, 7, 100.

Goldberg D and Williams P (1988) A User's Guide to the General Health Questionnaire., Windsor, NFERNelson.

Goldberg DP, Gater R, Sartorius N, Ustun TB, Piccinelli M, Gureje O and Rutter C (1997) The validity of two versions of the GHQ in the WHO study of mental illness in general health care. Psychological Medicine, 27, 191-197. 
Goodman R (1999) The extended version of the Strengths and Difficulties Questionnaire as a guide to child psychiatric caseness and consequent burden. Journal of Child Psychology and Psychiatry, 40, 791801.

Goodman R, Meltzer H and Bailey V (1998) The Strengths and Difficulties Questionnaire: A pilot study on the validity of the self-report version. European Child and Adolescent Psychiatry, 7, 125-130.

Hirst M (2005) Carer distress: A prospective, population-based study. Social Science \& Medicine, 61, 697-708.

lacovou M and Skew A (2010) Household structure in the EU. ISER Working Paper Series. Colchester, Institute for Social and Economic Research.

Kelly Y and Bartley M (2010) Parent and child health. IN HANSON, K., JOSHI, H. \& DEX, S. (Eds.) Children of the 21st Century. The first five years. Bristol, Polity Press.

Kenny DA, Kashy DA and Cook WL (2006) Dyadic Data Analysis., New York, NY, The Guilford Press.

Kline RB (2010) Principles and Practice of Structural Equation Modeling. Third Edition., New York, NY, The Guilford Press.

Kuipers E, Watson P, Onwumere J, Bebbington P, Dunn G, Weinman J, Fowler D, Freeman D, Hardy A and Garety P (2007) Discrepant illness perceptions, affect and expressed emotion in people with psychosis and their carers. Social Psychiatry \& Psychiatric Epidemiology, 42, 277-283.

Lieberman MA and Fisher $L$ (1995) The impact of chronic illness on the health and well-being of family members. The Gerontologist, 35, 94-102.

Llewellyn G, McConnell D, Gething L, Cant R and Kendig H (2010) Health status and coping strategies among older parent-carers of adults with intellectual disabilities in an Australian sample. Research in Developmental Disabilities, 31, 1176-1186.

Lucas RE (2005) Time does not heal all wounds: A longitudinal study of reaction and adaptation to divorce. Psychological Science, 16, 945-950.

Lucas RE, Clark AE, Georgellis Y and Diener E (2003) Reexamining adaptation and the Set Point Model of happiness: Reactions to changes in marital status. Journal of Personality \& Social Psychology, 84, 527-539.

Luhmann M and Eid M (2009) Does it really feel the same? Changes in life satisfaction following repeated life events. Journal of Personality \& Social Psychology, 97, 363-381.

Luttik ML, Lesman-Leegte I and Jaarsma T (2009) Quality of life and depressive symptoms in heart failure patients and their partners: The impact of role and gender. Journal of Cardiac Failure, 15, 580-585.

Manor O, Matthews S and Power C (2001) Self-rated health and limiting longstanding illness: interrelationships with morbidity in early adulthood. International Journal of Epidemiology, 30, 600-607.

Muthén LK and Muthén BO (1998-2010) Mplus User's Guide. Sixth Edition, Los Angles, CA, Muthén \& Muthén.

O'Reilly D, Connolly S, Rosato M and Patterson C (2008) Is caring associated with an increased risk of mortality? A longitudinal study. Social Science \& Medicine, 67, 1282-1290.

OECD (2009) What are equivalence scales?, OECD, [online] Available at: http://www.oecd.org/dataoecd/61/52/35411111.pdf [Accessed March 10 2011]

Office for National Statistics (2009a) National population projections, 2008-based. IN OFFICE FOR NATIONAL STATISTICS (Ed.) Statistical Bulletin. Newport, ONS.

Office for National Statistics (2009b) Social Trends No 39, Basingstoke, Palgrave Macmillan.

Office for National Statistics (2010) Social Trends No 40, Basingstoke, Palgrave Macmillan.

Payne $\mathrm{N}$ and Saul C (2000) What common disorders do those reporting limiting long-term illness experience, and what is their survivial and health service utilization experience? Journal of Public Health Medicine, 22, 324-329.

Poulin MJ, Brown SL, Ubel PA, Smith DM, Jankovic A and Langa KM (2010) Does a helping hand mean a heavy heart? Helping behavior and well-being among spouse caregivers. Psychology \& Aging, 25, 108-117.

Power C, Li L and Manor O (2000) A prospective study of limiting longstanding illness in early adulthood. International Journal of Epidemiology, 29, 131-139.

Pruchno R, Wilson-Genderson M and Cartwright FP (2009) Depressive symptoms and marital satisfaction in the context of chronic disease: A longitudinal dyadic analysis. Journal of Family Psychology, 23, 573-584. 
Rodrigues N and Patterson JM (2007) Impact of severity of a child's chronic condition on the functioning of two-parent families. Journal of Pediatric Psychology, 32, 417-426.

Royston P (2009) Multiple imputation of missing values: Further update of ice, with an emphasis on categorical variables. Stata Journal, 9, 466-477.

Sacker A, Head J and Bartley M (2008) Impact of coronary heart disease on health functioning in an aging population: Are there differences according to socioeconomic position? Psychosomatic Medicine, 70, 133-140.

SAS Institute Inc. (2003) SAS/STAT Software. SAS. 9.1 ed. Cary, NC.

Siegrist J and Wahrendorf M (2009) Participation in socially productive activitites and quality of life in early old age: Findings from SHARE. Journal of European Social Policy, 19, 317-326.

Sieh DS, Meijer AM, Oort FJ, Visser-Meily JMA and Van der Leij DAV (2010) Problem behavior in children of chronically ill parents: A meta-analysis. Clinical Child and Family Psychology Review, 13, 384-397.

Stajduhar KI, Funk L, Toye C, Grande GE, Aoun S and Todd CJ (2010) Part I: Home-based family caregiving at the end of life: A comprehensive review of published quantitative research (1998-2008). Palliative Medicine, 24, 573-593.

StataCorp (2009) Stata Statistical Software: Release 11. College Station, TX, StataCorp LP.

Stewart-Brown S, Tennant A, Tennant R, Platt S, Parkinson J and Weich S (2009) Internal construct validity of the Warwick-Edinburgh Mental Well-being Scale (WEMWBS): a Rasch analysis using data from the Scottish Health Education Population Survey. Health and Quality of Life Outcomes, 7, 15.

Verhulst FC (1995) A review of community studies. IN VERHULST, F. C. \& KOOT, H. M. (Eds.) The Epidemiology of Child and Adolescent Psychopathology. Oxford, Oxford University Press.

Ware JE, Kosinski M, Turner-Bowker DM and Gandek B (2001) How to Score Version 2 of the SF-12 ${ }^{\circledR}$ Health Survey (With a Supplement Documenting Version 1). , Lincoln, RI, QualityMetric Incorporated.

Wywich KW, Tierney WM and Wolinsky FD (1999) Further evidence supporting an SEM-based criterion for identifying meaningful intra-individual changes in health-related quality of life. Journal of Clinical Epidemiology, 52, 871-873.

\section{Appendices}

\section{Appendix 1. Statistical analyses}

This appendix provides detailed descriptions of the measurement and structural models estimated in this paper. Five total measurement models were estimated. Two for the partners, one for each age group; one for the adult children, one for parents of young children and one for the older parents of adult children.

\section{Partner health and well-being model}

The latent variable Actor-Partner Independence Model (APIM) (Cook and Kenny 2005 ; Kenny et al 2006) is comprised of two parts: a measurement model describing the relationship between a latent well-being variable and the three indicators of wellbeing (GHQ-12, SWEMWBS and life satisfaction) and a structural model that estimates the paths between dependent and independent variables, the variance and covariance between independent variables and the variance of the error in the dependent variable (Kline 2010). The measurement and structural models are estimated simultaneously and are represented by equations (1) and (2) respectively:

$$
\begin{aligned}
& \mathbf{Y}_{\mathrm{i}}=\boldsymbol{\Lambda} \boldsymbol{\eta}_{\mathrm{i}}+\varepsilon_{\boldsymbol{i}} \\
& \boldsymbol{\eta}_{\boldsymbol{i}}=\boldsymbol{\Gamma} \mathbf{X}_{\mathrm{i}}+\zeta_{\boldsymbol{i}}
\end{aligned}
$$

The subscript $i$ refers to the observational unit, in this case, the partnership. $\mathbf{Y}$ is a $6 \times 1$ matrix of dependent variables $\left(\begin{array}{llll}y_{1} & \ldots . & y_{6}\end{array}\right)$. These are the 3 measures of SWB for the two partners. $\mathbf{X}$ is a $q \times 1$ matrix of independent variables $\left(X_{1} \ldots . . . X_{p}\right)$, i.e. LLTI of the two partners and the model covariates. $\eta$ is a $2 x$ 1 matrix of latent variables, i.e. the SWB of each partner. Then $\Lambda$ is a $6 \times 2$ matrix of factor loading coefficients, $\Gamma$ is a $2 \times \mathrm{q}$ matrix of regression coefficients and the $\varepsilon$ and $\zeta$ are $6 \times 1$ and $2 \times 1$ matrices of normally distributed residuals with mean 0 and variance covariance $6 \times 6$ matrix $\Theta$ and $2 \times 2$ matrix $\Psi$, respectively. A graphical representation of the APIM model is given in figure A1. 
Figure A1. The actor-partner interdependence model of subjective well-being (SWB) and limiting long-term illness (LLTI)

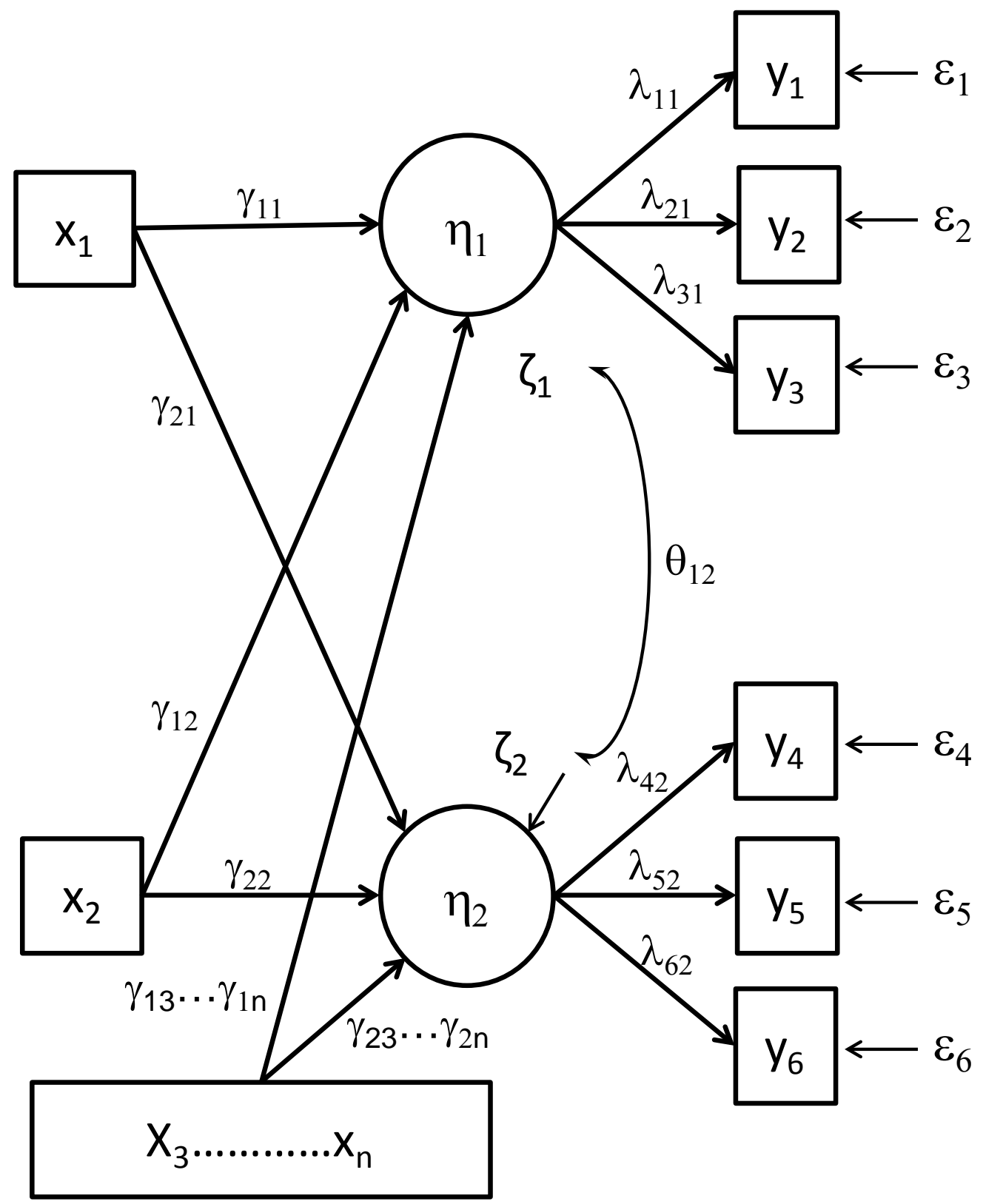

Key: $x_{1}$ actor $L L T I ; x_{2}$ partner $L L T I ; x_{3} \ldots . . . . x_{n}$ covariates; $\eta_{1}$ actor latent SWB; $\eta_{2}$ partner latent SWB; $y_{1}$ actor GHQ-12; $y_{2}$ actor SWEMWBS; $y_{3}$ actor life satisfaction; $y_{4}$ partner GHQ-12; $y_{5}$ partner SWEMWBS; $y_{6}$ partner life satisfaction; $\lambda_{11} \ldots . \lambda_{62}$ are the loadings of actor and partner latent $S W B$ on the observed measures; $\gamma_{11} \ldots . \gamma_{2 n}$ are the regression effects of the covariates on actor and partner latent $S W B ; \varepsilon_{1} \ldots . . . \varepsilon_{6}$ dependent variable residuals; $\zeta_{1}, \zeta_{2}$ latent $S W B$ residuals. 


\section{Parent health and adult children's well-being model}

In order to explore the relationship between the LLTI of parents over retirement age and their coresident adult children's well-being, a one-withmany design was used. This was specified as a twolevel latent variable model, with children at level 1 nested within parents at level 2. The observed indicators of adult children's SWB $\left(y_{1} y_{2}, y_{3}\right)$, can be decomposed into two components: the family means of each indicator and individual deviations from the family means, such that

$$
Y=Y_{1}+Y_{2}
$$

The equations for level 1 of the latent variable model are then:

$$
\begin{aligned}
& \Upsilon_{1 \mathrm{ij}}=\Lambda_{1} \eta_{1 \mathrm{ij}}+\varepsilon_{1 i j} \\
& \eta_{1 i j}=\Gamma_{1} X_{1 \mathrm{ij}}+\zeta_{1 i}
\end{aligned}
$$

And the equations for level 2 are:

$$
Y_{2 \mathrm{i}}=v+\Lambda_{2} \eta_{2 \mathrm{i}}+\varepsilon_{2 i}
$$

$$
\eta_{2 i}=\Gamma_{2} \mathbf{X}_{2 i}+\zeta_{2 i}
$$

The subscript $i$ refers to the level 2 unit, in this case, the parent and the subscript $j$ refers to the level 1 units, the adult children. $\boldsymbol{Y}_{\mathbf{1}}$ is a $3 \times 1$ vector of within family variation of the dependent variables $\left(y_{1} \ldots . . y_{3}\right)$ with zero means. $\Upsilon_{2}$ is a $3 \times 1$ latent variable vector of between family variation in the dependent variables ( $11 \ldots . . \mathrm{y} 3$ ) with $v$ a $3 \times 1$ vector of their intercepts. $\boldsymbol{X}_{\mathbf{1}}$ is an $\mathrm{n} \times 1$ vector of independent child variables $\left(x_{1} \ldots . . x_{n}\right)$, and $\boldsymbol{X}_{2}$ is an $\mathrm{m} \times 1$ vector of independent parent variables, i.e. LLTI of the parent and the family level covariates. $\eta_{1}$ is a latent variable, i.e. the SWB of the children. Then $\Lambda_{1}$ and $\Lambda_{2}$ are $3 \times 1$ vectors of factor loading coefficients with a $3 \times 1$ vector of residual variances, $\varepsilon . \Gamma_{1}$ and $\Gamma_{2}$ are $1 \times n$ and $1 \times m$ vector of regression coefficients and $\zeta_{1}$ and $\zeta_{2}$ are the residual variances in SWB at level-1 and level 2, respectively. A graphical representation of the latent variable one-with-many model is given in figure $\mathrm{A} 2$. 
Figure A2. The one-with-many model of limiting long-term illness (LLTI) in a parent and subjective well-being (SWB) of adult children

Level-2

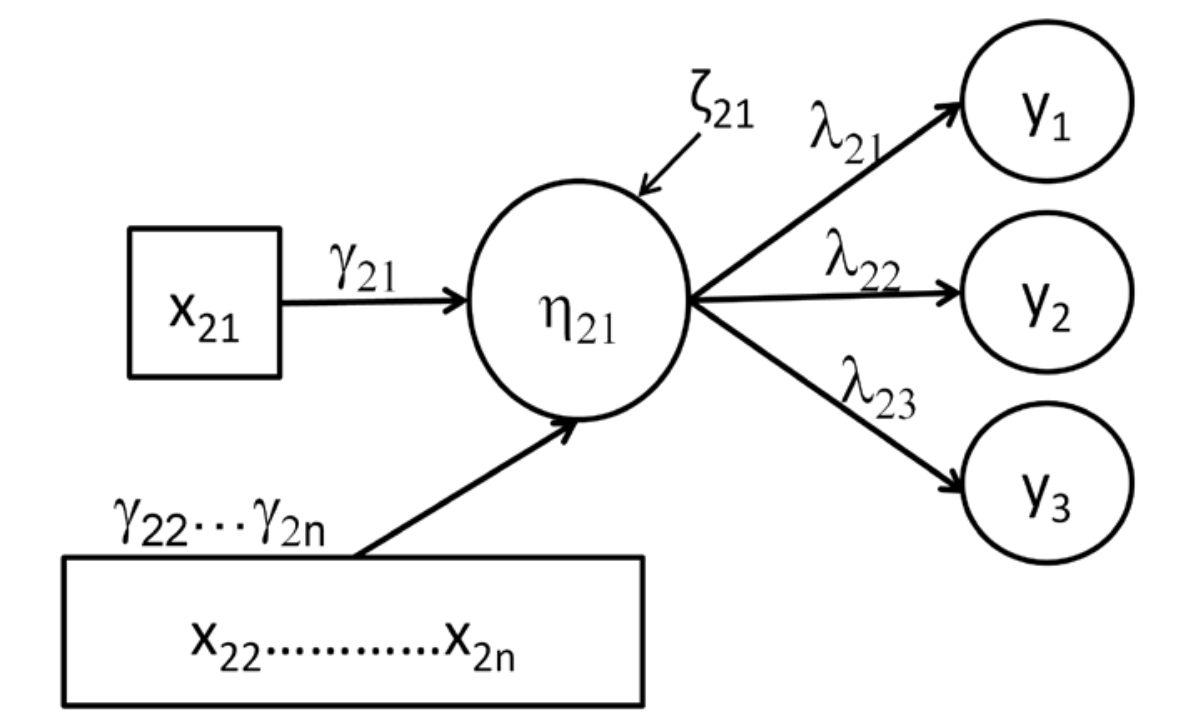

Level-1

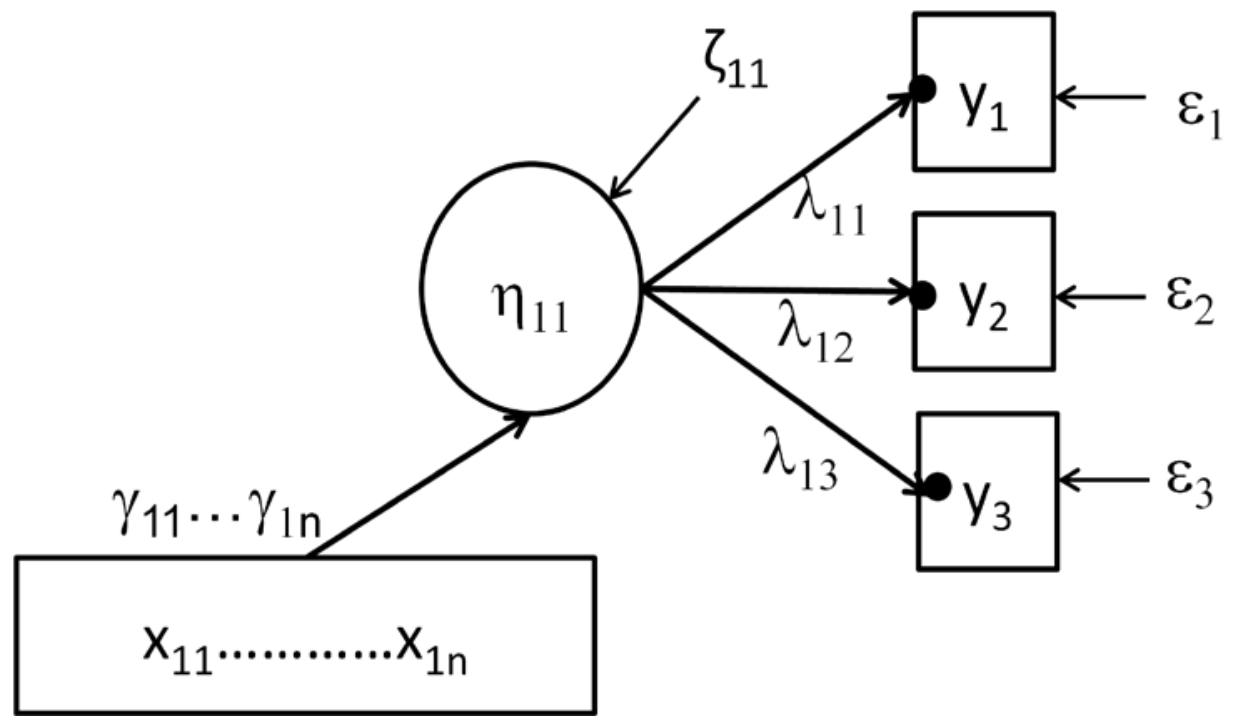

Key: $x_{21}$ parent $L L T I ; x_{22} \ldots \ldots . x_{2 n}$ parent covariates; $x_{11} \ldots \ldots . . x_{1 n}$ child covariates; $\eta_{1}$ child SWB; $y_{1}$ child GHQ-12; $y_{2}$ child SWEMWBS; $y_{3}$ child life satisfaction; $\lambda_{11} \ldots . \lambda_{31}$ are the loadings of child latent SWB on the observed measures; $\gamma_{11} \ldots \gamma_{2 n}$ are the regression effects of the covariates at level-1 and level- 2 on adult child latent $S W B ; \varepsilon_{1} \ldots . . . . \varepsilon_{3}$ dependent variable residuals; $\zeta_{21}, \zeta_{22}$ latent SWB residuals. The filled circles at the end of the arrows in the level-1 model represent random intercepts. In the level-2 model the random intercepts are shown as latent variables labelled $y_{1} y_{2} y_{3}$. 
Parent health and adolescent children's wellbeing model

The third type of analysis is used to examine the association between parents' LLTI status and their adolescent child's SDQ total difficulties score. This one-with-many model was again estimated using a two-level model, with children at level 1 nested within parents at level 2. While SWB was measured using a latent variable in the adult child analysis, here observed SDQ measures indicate younger children's well-being. The equations for the twolevel or random intercepts model are:

$$
\begin{aligned}
& y_{i j}=\Gamma_{1} X_{1 i j}+\varepsilon_{i j} \\
& y_{i}=B+\Gamma_{2} X_{2 i}+v_{i}
\end{aligned}
$$

$\boldsymbol{y}_{\boldsymbol{i}}$ is the SDQ score for child $j$ in family $i, \boldsymbol{y}_{\boldsymbol{i}}$ is the mean SDQ score for children in family $i, X_{1}$ is an $n x$ 1 vector of independent child variables $\left(x_{1} \ldots . . x_{n}\right)$, and $\boldsymbol{X}_{2}$ is an $\mathrm{m}$ by 1 vector of independent family variables. Then $\boldsymbol{B}$ is the overall SDQ intercept, $\boldsymbol{\Gamma}_{\mathbf{1}}$ and $\Gamma_{2}$ are 1 by $n$ and $1 \times m$ vectors of regression coefficients and $\boldsymbol{\varepsilon}$ and $\boldsymbol{v}_{\mathbf{i}}$ are the residual variance in SDQ at level 1 and level 2, respectively.

\section{Child health and parents' well-being model}

The fourth and final type of analysis is that used to model the relationship between child health status and the well-being of their parents. A latent variable model is estimated, taking account of the clustering of mothers and fathers within households. The equations are of the form shown in (1) and (2), but here, the subscript $i$ refers to the parent. So $\mathbf{Y}$ is a $3 \mathbf{x}$ 1 vector of dependent variables $\left(y_{1} \ldots . . y_{3}\right)$, the 3 measures of SWB for the parent. $\mathbf{X}$ is a $q \times 1$ vector of independent variables $\left(X_{1} \ldots . . X_{p}\right)$, i.e. any child in the household with a LLTI and the model covariates. $\boldsymbol{\eta}$ is a latent variable, i.e. the SWB of the parent. Then $\boldsymbol{\Lambda}$ is a $3 \times 1$ vector of factor loading coefficients, $\Gamma$ is a 1 $x q$ vector of regression coefficients and the $\varepsilon$ and $\zeta$ are the residuals of $\mathbf{Y}$ and $\boldsymbol{\eta}$, with mean 0 and $3 \times 3$ variance covariance matrix $\Theta$ and variance $\psi$, respectively.

\section{Appendix 2}

\section{Measurement model estimates}

This appendix provides a table of the standardised estimates for the five measurement models described in Appendix 1.

The well-being measures loaded well onto the latent variable for all models. The positive measures, SWEMWBS and life satisfaction fell between 0.54 and 0.85 while the GHQ-12 fell between -0.69 and -0.78 .

Examination of the modification indices only yielded significant results for the partner model. The suggestions resulted in the addition of two covariances, one between Partner 1 and Partner 2 GHQ-12 variance and the second between Partner 1 and Partner 2 life satisfaction variances. These covariances indicate that there may be a correlation between the distress or life satisfaction of one partner and the distress or life satisfaction of the other partner. Essentially, partner's scores of these two well-being measures are more similar than non-partnered persons. 
Table A1. Standardised estimates for measurement models

\section{Partner Model}

\section{6-59/64 Age Group 60/65+ Age Group}

$\beta \quad$ SE

$-0.76 * * * *$

$0.82 * * * *$

0.01

$0.61 * * * * \quad 0.01$

$-0.77 * * * * \quad 0.01$

$0.80 * * * *$

$0.60 * * * *$

$0.43 * * * *$

$0.33 * * * *$

$0.63 * * * *$

$0.41 * * * *$

$0.35 * * * *$

$0.64 * * * *$

1.00

1.00

$\zeta_{2}$

\section{Covariance}

$\begin{array}{lllll}\eta_{1}, \eta_{2} & 0.38 * * * * & 0.02 & 0.45^{* * * *} & 0.04 \\ \varepsilon_{1}, \varepsilon_{4} & 0.10^{* * * *} & 0.04 & 0.10^{*} & 0.05 \\ \varepsilon_{3}, \varepsilon_{6} & 0.13^{* * * *} & 0.02 & 0.04 & 0.03\end{array}$

$0.53 * * * * \quad 0.02$

$-0.75 * * * * \quad 0.02$

$0.73 * * * *-0.02$

0.01

$44 * * * * \quad 0.02$

0.02

0.02

$0.020 .47^{* * * *} \quad 0.03$

0.02

$--\quad 1.00$

$--\quad 1.00$

\section{Adult Child Model}

$\beta$

$0.85 * * * *$

$0.72 * * * *$

$0.41 * * * *$

$0.27 * * * *$

$0.48^{* * * *}$

0.06

0.07

0.07

CFI $\quad 0.99$

TLI 0.98

$\chi^{2} \quad(d . f .=22, N=5236)=98.63, p<0.0001$

RMSEA $\quad 0.04,95 \% \mathrm{Cl}=(0.03,0.04)$

${ }^{*}<0.05 ;{ }^{* *}<0.01 ; * * *<0.001 ; * * * * 0.0001$

d.f. $=$ Degrees of Freedom; RMSEA $=$ Root Mean Square Error of Approximation

1.00

1.00

1.00

0.00

\section{Parent of Adult Child}

$\beta$

SE

$-0.69 * * * * \quad 0.06$

$0.78 * * * * \quad 0.06$

$0.59 * * * *$

0.06

0.06

$0.81 * * * *$

$0.64 * * * *$

Parent of Youth

SE

(d.f. $=0, N=254)=0.00, p=0.00$
1.00

1.00

(d.f. $=0, N=254)=0.00, p=0.00$

0.00
1.00

1.00

(d.f. $=0, N=3074)=0.00, p=0.00$

0.00 


\section{Appendix 3}

\section{Descriptive statistics for imputed data}

Tables A2 and A3 provide the descriptive statistics from the complete case data for partners and correlations of variables which construct the children, respectively. Table A4 provides the outcome latent variable for partners, calculated from the imputed data.

\section{Table A2. Descriptive statistics of partners by age group*}

\begin{tabular}{|c|c|c|c|c|c|c|c|}
\hline \multirow[b]{2}{*}{ LLTI (\% Yes) } & \multicolumn{2}{|c|}{$\begin{array}{l}\text { Overall } \\
N=4499\end{array}$} & \multicolumn{2}{|c|}{$\begin{array}{c}16-59 / 64 \\
n=3496\end{array}$} & \multicolumn{2}{|c|}{$60 / 65+$} & p-value ${ }^{+}$ \\
\hline & & & & & & & \\
\hline Partner 1 & 23 & -- & 18 & -- & 40 & -- & $<0.0001$ \\
\hline Partner 2 & 23 & -- & 19 & -- & 38 & -- & $<0.0001$ \\
\hline \multicolumn{8}{|c|}{ Care for Partner (\% Yes) } \\
\hline Partner 1 & 5 & & 4 & & 10 & & $<0.0001$ \\
\hline Partner 2 & 4 & & 3 & & 10 & & $<0.0001$ \\
\hline \multicolumn{8}{|l|}{ Age } \\
\hline Partner 1 & 47.95 & 15.16 & 43.07 & 11.72 & 70.59 & 5.95 & $<0.0001$ \\
\hline Partner 2 & 48.46 & 15.49 & 43.58 & 12.25 & 71.07 & 5.94 & $<0.0001$ \\
\hline \multicolumn{8}{|l|}{ GHQ Score } \\
\hline Partner 1 & 10.76 & 4.79 & 10.92 & 4.89 & 10.21 & 4.38 & $<0.0001$ \\
\hline Partner 2 & 10.75 & 4.85 & 10.93 & 5.00 & 10.13 & 4.25 & $<0.0001$ \\
\hline \multicolumn{8}{|l|}{ SWEMWBS } \\
\hline Partner 1 & 25.41 & 4.20 & 25.20 & 4.15 & 26.16 & 4.30 & $<0.0001$ \\
\hline Partner 2 & 25.59 & 4.22 & 25.39 & 4.26 & 26.29 & 4.04 & $<0.0001$ \\
\hline \multicolumn{8}{|c|}{ Life Satisfaction } \\
\hline Partner 1 & 5.43 & 1.31 & 5.34 & 1.30 & 5.76 & 1.28 & $<0.0001$ \\
\hline Partner 2 & 5.42 & 1.33 & 5.33 & 1.34 & 5.75 & 1.22 & $<0.0001$ \\
\hline \multicolumn{8}{|c|}{ SF-12 Physical Functioning } \\
\hline Partner 1 & 50.18 & 10.58 & 51.57 & 9.43 & 43.75 & 12.98 & $<0.0001$ \\
\hline Partner 2 & 49.97 & 10.85 & 51.20 & 10.00 & 44.24 & 12.69 & $<0.0001$ \\
\hline \multicolumn{8}{|c|}{ SF-12 Mental Functioning } \\
\hline Partner 1 & 51.77 & 8.84 & 51.31 & 8.74 & 53.90 & 8.98 & $<0.0001$ \\
\hline Partner 2 & 51.77 & 8.97 & 51.30 & 8.94 & 53.96 & 8.77 & $<0.0001$ \\
\hline
\end{tabular}

* Age, Partner 1 and 2 GHQ-12 Score, Partner 1 and 2 SWEMWBS Score and Partner 1 and 2 Life Satisfaction Score are means and standard deviations; SWEMWBS = Short Warwick-Edinburgh Mental Well-being Scale; LLTI = Limiting Longterm IIIness; SF-12 PCS and MCS = Short Form 12-item Physical and Mental Component Scores

${ }^{+} p$-value for Gender, Partner 1 and 2 IIIness, Partner 1 cares for Partner 2 and Partner 2 cares for Partner 1 based on $X^{2}$; $p$-value for Age, Partner 1 and 2 GHQ-12 Score, Partner 1 and 2 SWEMWBS Score, Partner 1 and 2 Life Satisfaction Score and Partner 1 and 2 SF-12 Physical and Mental Functioning based on least squares mean comparisons 


\section{Table A3. Descriptive statistics of adult children and youth by gender ${ }^{*}$}

\begin{tabular}{|c|c|c|c|c|c|c|c|}
\hline \multirow{3}{*}{$\begin{array}{l}\text { Adult Children }(\mathbf{n}=\mathbf{2 3 4}) \\
\text { Gender }(\%)\end{array}$} & \multicolumn{2}{|c|}{ Overall } & \multicolumn{2}{|c|}{ Males } & \multicolumn{2}{|c|}{ Females } & \multirow[t]{2}{*}{ p-value $^{+}$} \\
\hline & & & & & & & \\
\hline & & & 56 & -- & 44 & -- & 0.07 \\
\hline Adult Child LLTI (\% Yes) & 25 & -- & 26 & -- & 24 & -- & 0.75 \\
\hline Parent LLTI (\% Yes) & 44 & -- & 40 & -- & 50 & -- & 0.17 \\
\hline Care for Parent (\% Yes) & 20 & -- & 17 & -- & 24 & -- & 0.16 \\
\hline Age & 37.06 & 12.29 & 36.89 & 11.85 & 37.29 & 12.88 & 0.80 \\
\hline GHQ-12 Score & 11.29 & 6.01 & 11.12 & 5.38 & 11.50 & 6.74 & 0.64 \\
\hline SWEMWBS Score & 24.49 & 4.75 & 24.27 & 4.83 & 24.77 & 4.65 & 0.42 \\
\hline Life Satisfaction Score & 5.07 & 1.50 & 4.92 & 1.48 & 5.27 & 1.52 & 0.07 \\
\hline \multicolumn{8}{|l|}{ Youth $(n=2594)$} \\
\hline Gender (\%) & & & 50 & -- & 50 & -- & 0.88 \\
\hline Cared for by Parent (\% Yes) & 2 & -- & 3 & -- & 1 & -- & 0.001 \\
\hline Parent LLTI (\% Yes) & 19 & -- & 21 & -- & 17 & -- & 0.01 \\
\hline Age & 12.98 & 1.40 & 12.95 & 1.46 & 13.02 & 1.44 & 0.19 \\
\hline SDQ Total Diffculties Score & 11.04 & 5.45 & 11.02 & 5.66 & 11.05 & 5.23 & 0.89 \\
\hline Parent SF-12 PCS & 51.69 & 9.49 & 54.49 & 9.73 & 51.89 & 9.26 & 0.29 \\
\hline Parent SF-12 MCS & 49.54 & 9.95 & 49.46 & 9.62 & 49.63 & 10.26 & 0.65 \\
\hline
\end{tabular}

*Age, SDQ Total Difficulties Score, GHQ-12 Score, SWEMWBS Score and Life Satisfaction Score are means and standard deviations; SDQ = Strengths and Difficulties Questionnaire; SWEMWBS = Short Warwick-Edinburgh Mental Well-being Scale; LLTI = Limiting Long-term IIIness; SF-12 PCS and MCS = Short Form Physical and Mental Component Scores - $p$-value for Gender, Adult Child and Parent LLTI and Care for Parent/Cared for by Parent based on $X^{4}$; $p$-value for Age, GHQ12, SWEMWBS, Life Satisfaction, SDQ Total Difficulties Score and Parent SF-12 Physical and Mental Functioning based on least squares mean comparisons

Table A4. Correlations of outcome variables - partners, by age group

\begin{tabular}{|c|c|c|c|c|c|c|}
\hline & \multicolumn{5}{|c|}{ Partner 1} & \multirow{3}{*}{$\begin{array}{c}\text { Partner } 2 \\
\text { Life } \\
\text { Satisfaction }\end{array}$} \\
\hline & Partner 1 & Partner 1 & Life & Partner 2 & Partner 2 & \\
\hline & GHQ-12 & WEMWBS & Satisfaction & GHQ-12 & WEMWBS & \\
\hline Partner 1 GHQ-12 & -- & -0.55 & -0.35 & 0.27 & -0.22 & -0.17 \\
\hline Partner 1 WEMWBS & -0.62 & -- & 0.41 & -0.21 & 0.28 & 0.18 \\
\hline Partner 1 Life Satisfaction & -0.45 & 0.49 & -- & -0.17 & 0.18 & 0.14 \\
\hline Partner 2 GHQ-12 & 0.25 & -0.25 & -0.22 & -- & -0.54 & -0.39 \\
\hline Partner 2 WEMWBS & -0.18 & 0.25 & 0.19 & -0.62 & -- & 0.42 \\
\hline Partner 2 Life Satisfaction & -0.19 & 0.21 & 0.25 & -0.49 & 0.47 & -- \\
\hline
\end{tabular}

